\title{
PRIVATE SECURITY THROUGH THE PRISM OF PRIVATE SECURITY DEVELOPMENT STRATEGY IN THE REPUBLIC OF MACEDONIA
}

\author{
OLIVER BAKRESKI, PhD \\ Ss. Cyril and Methodius University - Skopje, \\ Faculty of Philosophy \\ Institute of Security, defense and peace \\ E-mail: oliverbakreski@yahoo.com
}

\begin{abstract}
The Development strategy for the private security comprises concrete goals and measures of whose operationalization should contribute for the development of the private security activity. The scientific explanation in this effort is based on two approaches. First, the research is founded on the scope of the basic theoretical assumptions about the terminological divergent for the notion strategy and its use, and afterwards follows a perception of the Development strategy for the private security in the Republic of Macedonia through the prism of the strategic goals.
\end{abstract}

Key words: strategy, strategic goals, development, private security, private protection.

\section{Introduction}

The creation of an appropriate strategy counterpoises a process throughout the efforts for building an internally complied, respectfully, non-contradictory performance by its bearer, which unifies the theoretic, experiential and intuitively based acknowledgements for the problem, on one hand, and regard on the partial interests' 
positions and views of the problem on the other (Hilsman, R., 1993, p.36-89). Hence, the term strategy itself implicitly presupposes the existence of the necessary interaction of theory and practice, knowledge and skills, in order to successfully apply the appropriate methods and means on all levels in the accomplishment of the planned goals. That is why the scientific and expert comprehension of the essence itself and the context of the strategy based on which the real plans can be brought has especially crucial significance. This conclusion leads us to the ascertainment that this process is exceptionally difficult and followed by certain specifics and factors which influence its shaping Maslesa R., 2001, p. 146).

So, for an effective strategy it could be discussed if the same is based on scientific findings. They should be the basic substrate in the shaping of its frame, and it should create a relevant basis for an appropriate designation of the sole priorities and goals. Also, the findings should offer adequate means to approach and accomplish the designated goals. Likewise, it could be said that the strategy as a planning document is a framework through which the fundamental priorities are underlined as well as certain goals which are usually presented in an integrated single document. This document, has a present and future role, draws out the key development directions and defines the means for the approach and fulfillment.

\section{General outlooks}

Entering a debate for the discourse of the private security activity, it could be said that the development of the activity always depends from a well elaborated and clearly formulated strategy. The segment of issues related with the private security activity, are a challenge for the subjects involved in the private security, while various other segments of the issues are a concern for various institutions, respectfully, numerous different institutions in today's conditions designated their own development strategy. Still, regardless the subject, or institution the strategy which is brought carries certain factors which significantly determine their policy for the development of the activity itself.

In that notion, a double provocation for every organization, institution etc. is the respect of the elements with common significance, as well as the elements with national significance, because that process is conditioned with good knowledge for the 
general and the special specifics which directly respond to the demands of the contemporary reality.

In the approach of the creation of a certain strategy, the answers of the following questions should be consisted: " 0 n which principles is the strategy based?", "What kind of strategy is necessary?", "What goals should be achieved?", "Which is the most optimal method for achieving the goals?", "Which means and how much resources are needed for achieving the goals?" etc.

The answer of these questions is not easy, nor simple, yet it is intricate, complex and multidimensional because it depends from numerous factors, some objective, and some subjective. Hence, by default, the conducting of the goals demands a lot of effort, knowledge, energy, resources, and potentials. That is why it is important to prepare a comprehensive strategy in which all the relevant actors would be included and all the aspects in the development of the activity will be taken into account. Only this approach will give an opportunity to the subject to realize the concrete goals in an integrated and comprehensive way.

It means that the process of guaranteeing an optimal degree of development of the private security activity is a complex process which demands a great amount of knowledge, and the strategic goals quoted in the Strategy for development of the private security as professionalization, providing a quality work force, public- private partnerships, protection of the critical infrastructure and building trust in the community should be based on the strict democratic principles ensuring transparency and accountability in the process.

\section{Strategic aspects and goals}

The Strategy for development of the private security in the Republic of Macedonia brought in 2016 should be in accordance with the contemporary trends in the regulation and practice in this sphere. It is necessary to emphasize the preventive character of the private security through building an optimal model of development of the private security and consequently, decrease the losses caused by human error, 
negligence, criminal activities and natural disasters. ${ }^{241}$ Beside this general goal, the Strategy had designated several strategic goals which are expected to bring a concrete contribution in the development of the private security activity. The key strategic goals defined with the Strategy for development of the private security in the Republic of Macedonia are: professionalization, providing a quality work force, public- private partnerships, and protection of the critical infrastructure and building trust with the community.

\subsection{Professionalization as a strategic goal}

Basically, in none of the contemporary argumentations on security, defense, healthcare, administration, etc. the topic of professionalization is avoided, because it is an omnipresent phenomenon which occurs in every segment of society. The solution to this issue is a major concern not only for the institutions, organs and organizations, the business community, but also for the public safety and the country in general. Hence, it is not all the same what steps are taken in this plan and especially the issue how to achieve better professionalization in the subjects dominated by the security component, as a natural element of the security structure.

From the aspect of achieving security there is no dilemma that the subjects responsible for security have to hold enough power and authority to perform their work, but not in an extent which would jeopardize the wellbeing of the society or the individual.

Therefore, the normal response to this dilemma underlines three aspirations: legitimacy, professionalism and accountability. For this reason, the main goals are directed toward continuous legitimacy, permanent professionalism and constant accountability. All three conditions have to exist and be fulfilled in order to discuss a democratic governance. The professional behavior and accountability corroborates legitimacy, while accountability enables professionalism, and legitimacy enables the necessary degree of professional independency. (Bakreski, 0., 2012).

In general, accountability signifies a proactive approach for one self, protection for one self and others, responsibility toward the state, toward the values etc.

\footnotetext{
${ }^{241}$ Development strategy for private security in the Republic of Macedonia, Chamber of Republic of Macedonia for private security, Skopje, 2016, p. 20.
} 
Professionalism means also a participatory share and contribution, as well as an idea how to stimulate creativity which basically means innovation, determination and taking action in order to provide changes in a security notion of the term.

Professionalism defines three charatceristics, which are: expertise, responsibility and corporacy. ${ }^{242}$ In that direction, the 0xford dictionary, when defining the professionalism these aspects are always taken into account: expertise and specialized skills, motivation (with a financial compensation), acquaintance with theoretic knowledge as well as connection with certain working matters (social status).

Altruism, transparency, integrity, service, respect and honor are also a part of the characteristics of professionalism. The concept and the theoretical basis for professionalism during the performance of the work are implemented during the period of education and qualification (Wear, D, Bickel, J., 2000).

It means that professionalism is a categorical feature regarding certain values, skills, orientation and management. The principles of fair behavior, integrity, human rights vigilance, accountability and adequate use of force are the basic elements in every concept of democratic rule. Professionalism must not be involved in discriminatory, corrupt and violent exploitation of its power. Independence (limitation) which the private security sector has is based on the trust of society that this sector will accept part of the values which are determined by the democratic equilibrium of ethical and professional rule (Fluri P., Hadžić M., eds., 2004).

Getting out from the embrace of the professionalism will result with rough, corrupted and incompetent behavior, and in certain cases could even lead to public scandals, which imposes the need for serious regulation of this sector (Born H. Caparini M. and Cole E., 2007).

\subsubsection{How to achieve better professionalization}

Professionalization is a dynamic category which is conditioned by numerous factors and is in tight correlation with the development of the society. In general, it is achieved on a prolonged period and it is determined by the democratic ambience in the country and by the relations between the subjects themselves in the society, starting from the family, schools, religious communities, security institutions, etc.

242 Military Professionalism in Asia: Conceptual and Empirical Perspectives. East West Center. 2001. 


\section{Secururity}

So, perceiving the problem of professionalization is solely possible only through detailed acquaintance of the complex, intertwined internal relations, as well as through consideration of the crucial elements which have the central role in the creation of a congruent working ambience starting from the environment, the achieved degree of education, the level of awareness ${ }^{243}$, the dynamics and the compexity of the relations in the sphere of security, social development, multi layer communication forms etc.

Herefrom, the basic issue which is raised is not "Wether a profesionalization is needed?"but the question " "How to achieve better professionalization?". In order to get to a greater profesionalization several conditions should be fulfiled, which are:

The first condition is the designation of minimum standards which will contribute for the development of the profesionalization in this sector. Professional knowledge is the fundamental pilar which appoints the commencements, the goals and the development of the professionalization process.

The second condition is the complete division of the work. With professionalization a complete division of the work is achieved. The strenghtening of the criteria for the internal organization and the systematization of the working positions should not only be considered for the managerial structures but also for the subordinate layers.

The third condition is evaluation of the work and the working process. Everything done must be a subject of evaluation. This element can be administered through strenghtening of the permanent measures for knowledge evaluation.

The fourth condition is especially underlined in the Strategy for development of the private security and it refers to the quality of the service and working. This is actually a continuous battle on how to impose, or "nominally", how to be sold on the market, but there is no doubt that it could be done only with a good and quality offer and work.

The fifth condition is accountability which goes hand in hand with professionalization. Accountability pressuposes explanation for a certain behavior and to be responsible toward external crtic. Accountability demands the responsibilities, authorizations and functions of the authorized bodies to be defined so the work of the

\footnotetext{
243 Awareness has a crucial significance for the future of the man, and it contributes to the citizens with their behavior and engagement to give a better support for the respective which has to be experienced from a different aspect, becoming aware of their legitimacy.
} 
subordinated could be successfully audited and evaluated. Accountability as a category is tied with performing the tasks in the anticipated time and in accordance with the prescribed standards. This leads toward a professional organization, which acts preventive with the purpose to preclude committing criminal acts.

Also, accountability signifies that the police will not act solely on its own assumptions for efficient and rational functioning, but it will take into consideration every expectation the community has for it (Bakreski, 0. 2010).

The sixth condition is related with professional competences and obtaining them is conditioned by the practical performance of the tasks, and here it comes to the fore the acquired knowledge.

This primarily means the subjects themselves to strive for an adequate personnel planning and to choose the best candidates due to the specification of the activity and the profession, and secondly, this concept has to comprise expert's profiles which will be succumbed of a continuous expert improvement, their appropriate preparation for the comprehension of every day's tasks and work etc.

The seventh condition is the assurance for political neutrality. The employees in the private security, respectfully the Security agencies should be apolitical, which would mean that they are committed to the work and professional conduction of the tasks. Basically, professionalization will enable performance of the tasks on lawful foundation, and on the basis of someone's wishes. It is a sort of guarantee that the employees will professionally perform their duties and that will be completely dedicated on their fulfillment which would mean a high degree of responsibility, which is in fact one of the elements required for their profession.

\subsection{Enabling a quality work force}

This concrete and undoubtedly priority goal is focused toward drawing a quality work force, due to the actual need of workers for the legal entities which perform the private security activity. It is a common impression that gradually this issue becomes troubling because the indicators speak that on the labor market there are less and less interested to work in the private security business. Here, several questions are raised: "What are the reasons?", "Which factors contribute for this condition?", "How to overcome this situation?", "Which mechanisms should be engaged in order to motivate young people to choose this profession?" The answer is maybe simple, but yet 


\section{Seccurity}

complicated because it is considered that attracting the interest of young people for engaging in the private security activity should not be tied solely for the financial motive, rather it should be a learning process for the importance of this segment, and it could be achieved in the educational process.

Education is a key factor and along with the training and specialization will contribute for a better professionalization and development of the private security activity. The knowledge obtained in the educational process is a main determinant in development because it is based on comprehending and gaining a complex corpus of competencies, abilities and skills. Knowledge obtained in the educational process means acquiring the necessary expertise, integrity, morality, altruism and skills for promoting the public wellbeing. All of these elements are shaping the grounds for the social agreement among professions and societies, which in return ensures the professional autonomy in the practice and the privilege for self-regulation. Professions are founded on specialized knowledge which is a basis for receiving the necessary quality. (0xford English Dictionary, 1989 0xford: Clarendon Press).

It means that it is a vocation which requires a specialized knowledge, a durable and intensive upgrade is often necessary, which involves learning based on scientific, historical or theoretical principles. That specialized knowledge is maintained through the power of the organization or with adjustment with the standpoints for high standards for performance and behavior, as well as with the approval from the members of the profession, continuous research and that kind of activity, which primarily purpose is performing public service (Merriam Webster (ed.), Webster's Third New International Dictionary, Unabridged. 2000 Springfield, MA: Merriam-Webster).

In contemporary conditions of labor market functioning, imposed above all because of the global specialization in the work, primarily for the companies and consequently transferred to the employees themselves, as well as because of the demand for educated, competent and qualified work force, an imperative counterpoises the expert knowledge, which prepares the candidate for a concrete profession, providing the necessary skills and knowledge for active work. In the spirit of such practices and experiences it is necessary to apostrophize that in the private security business there is a specific specialization, determined by the public authorities of the activity itself. ${ }^{244}$

\footnotetext{
244 Development strategy for the private security in the Republic of Macedonia, Chamber of Republic of Macedonia for private security, Skopje, 2016, p. 21-26.
} 


\section{Seccurity}

In the context of provision of the necessary competent and qualified work force permanent steps should be made for improvement of the education and continuous attainments. The improvement of the education and the continuous attainment are in the direction toward improvement of the capabilities and obtaining new skills through knowledge absorption which are needed for new forms and modes for providing a balanced process of decision making, but also for other new solutions with which concrete problems related to the work will be resolved. This is especially important for the employees in the private security sector because the continuous education of its personnel creates capable cadre, which could deal with certain difficulties any timer and can find solutions for the concrete security concerns.

So, a key factor for fulfilling this strategic goal is education. One of the solutions which is pointed out in the Strategy itself is consisted in the response for creation of educational- study programs. Of course, this step would mean a great leap and would be a solid basis for providing an adequate cadre which will be the bearing element in the above synthesized analysis.

\subsection{Public- private partnerships}

The achieved level of development and cooperation between the public and the private sector in a certain social- political system depends on numerous factors, among them: the place they hold in society, the method for deciding for the position and the role of these sectors in the country, their contribution and real significance, the financing mode for these sectors, the nature of the relations between the recipients of security and the providers, the working status of the employees providing services to a certain recipient etc. (Ahić J., 2009, p. 17-37).

This would mean that the frontier between the private and the public sector, instead of getting clearer, it will become more vague, making it more difficult to separate the traditional public police forces from their private colleges. (Johnson Brian, 2005, стр.419-420). Hence, the first crucial question is: "Is the sphere of action of public security equated with the private security?" respectfully "Can a comparison like this be made?" secondly, "For whose interest does this business serve?" and third: "Where is the line between private and public security?" If the answers to the questions is not in favor of the private security nor public security, then these thin lines could be described as "a grey" area which contours the margins themselves between those two subjects. It 
signifies that it is the complexity of the private security that makes it so close yet so different from public security which produces additional difficulties in drawing the line.

The following problem in the contouring of the borders of the public and the private security is the fact that there are many employees which perform security functions as part of their general duties, but to which these functions are not their main role and purpose. For example, a receptionist whose main duty is to accept guests and to answer questions, can also have a function in the part of the control of access and maybe even video monitoring. Would anyone consider this person working in the private security? Also, regular personnel such as janitors could be used to search for suspicious items if there is an alert for a bomb installment. Does that mean that if the janitor does that often is a part of the private security sector? Many citizens also do voluntary activities which can be interpreted as security functions, for example, schemes for monitoring the neighborhood, voluntary street patrols. Are these activities interpreted as a part of the private security sector? (Bruce George and Button Mark, 2004, p.14-15).

The comparison between the public and the private security, as well as the explication of the nature of the cooperation between these two sectors expressed through the actual public- private partnerships shows that there is a space for rapprochement of these two segments and that there is a clear need for their cohabitation in the achievement of the common goals although from a historical aspect, the relationship between the public and the private sector was not always the best. Sometimes the police underestimated the private security, which felt that the police has no interest in their domain of action. However, nowadays there is a tendency toward achieving these partnerships, whose main purpose is the progress and development of the public and the private security sector (Dempsey S.John, 2011, p.360). include:

Basically, the most common activities of the partnerships and cooperation

1. Establishing business and personal contacts;

2. Expansion of resources (the police can assist the private securers in the performance of their work, including contracting for certain noncriminal and harmless tasks for which police authority is not necessary, but also private security could come in handy to the police in countering corporate crime); 
3. Programs for crime prevention, joint participation in the security field, developing mutual methods for crime prevention and combining forces for achieving the common interests in countering video piracy, graffiti, false alarms and neighborhood watch programs;

4. Sharing resources, respectfully, borrowing the technical and terminological competency;

5. Enabling a legal framework which includes the support and draft laws;

6. Joint action, for example, in investigation of complex financial frauds or computer felonies; bringing mutual security plans for protection from natural disasters, gunfights and school violence as well as violence on the working place, joint operations for violations, such as street theft;

7. Investigation and creation of a guideline for preparation and review for: examination and protocols regarding false alerts, drug- related crimes on the working place, violence on the working place, internal info television etc (Dempsey S.John, 2011, p.360-362)

\subsection{Critical infrastructure protection}

The critical infrastructure as a vital, complex and reciprocally structurally connected entirety has an exceptional importance and significance for the uninterrupted function of the country. It is clear dialectics and synergy which connects the industrial sector, communication systems, the energy sector, the education sector, the health sector, telecommunications sector and other sectors, systems and networks of utmost importance for the country because it enables the necessary stability. From hence, the interruption or the disruption of the work of certain sectors/systems could lead to serious consequences which can have a weakening effect on the security of the country, on the national economy, on the economic development and prosperity, on the stabile energy sector, respectfully, the interruption or the disruption of the work of just one from the above mentioned sectors could lead to serious consequences over other critical sectors.

Basically, the segment of issues related with the critical infrastructure demands balance, common efforts and high level of cooperation between the key subjects. And that is way it is generally considered that the issues for critical infrastructure protection are one of the most hardest because they need to establish a 


\section{Securianues}

balanced system of relations between the subjects themselves which have to actively participate in this realm: the Ministry of interior, the Security agencies, the Chamber of the Republic of Macedonia for private security, the operators themselves and numerous other actors. All of it demands a serious anticipative approach and building an appropriate coherent policy.

On account of the complexity and difficulty itself of these matters, the critical infrastructure should be perceived in its totality so there won't be any one- sided, partial, segmented and insubstantial solutions, rather, it has to be approached systematically, thoroughly, completely pragmatic and through the prism of offering adequate solutions.

Otherwise, the critical infrastructure of the Republic of Macedonia is relatively new realm which is still not legally regulated, respectfully, there still is not legal framework for defining, identification and protection of the critical infrastructure, and with that, there is no formally designated critical infrastructure register. Yet, it has to be emphasized that the identification of the critical infrastructure will not start from the very beginning because it is founded on some existing acts which recognize this realm.

In particular, attention should be drawn on the Law for private security which singles out a specific Chapter 5 for the arrangement of the topic "Compulsory private security" which in Article 44, Paragraph 1 further delegates the obligation for designating the legal entities by the Government of the Republic of Macedonia.

It should be emphasized that not only in the Law for private security and other legal frameworks this segment is recognized in a sort of way. The issues are occurring only around the compliance and the terminological divergences about the notion and the use of this term.

It remains to be concluded that the critical infrastructure is the pillar of the country. That is how it is connected with the citizens and the country.

For the citizens it is the level of security of the crucial resources and capacities, having, respectfully, not having, food for survival, potable water, communication systems which are a fundamental need, healthcare, education, and other essential needs such as the necessary transportation: aerial, rail or road, widespread trade net, energy system etc.

For the country the critical infrastructure is tied for the national security, for the welfare, the national economic security, the economic development and prosperity, 


\section{Seccurity}

better health and public safety, better energy sector, better health sector, stabile energy sector etc.

From hence, the protection of the critical infrastructure should be particularly apostrophized because it is well known that this is an essential segment, respectfully it is a core part of the national security of every country, so hence its protection is a top goal and priority of every state, especially if it known that every country is exposed to the social deviations (for example thefts, frauds, industrial espionage, sabotage, diversions, malicious damages etc), natural disasters, technological and technical accidents, human errors etc., all of them can cause massive human losses and material damage. If certain specific forms of imperilment are added up to these elements, within the framework of which subsides the use of contemporary weapons and advanced technologies, including nuclear material, chemical and biological weapons and similar, all of this is a clear signal that there is a serious security risk refueled with the possibility such weapon to be used in illegal acts over the critical infrastructure, it imposes the need for the creation of appropriate defense mechanisms for the critical infrastructure.

It emanates from the above mentioned, that the critical infrastructure is an omnipresent phenomenon for which the complete effectuation of a large amount of knowledge, pragmatism and experience is necessary, and most importantly, an appropriate anticipative approach of the subjects engaged in the process in order to unify all of the resources.

This in perspective should mean:

$\sqrt{ } \quad$ The private security should impose as a serious player in this story because it has a crucial role in the protection and the securing of the critical infrastructure in our country, to that, its experience, position and function must be respected during the preparation of other legal acts in the realm of critical infrastructure protection in the future, and the good practice of the private security has to be a basis of practice in this sphere.

$\sqrt{ }$ A comprehensive public debate should be opened for all the segments, in order to initiate a legal regulation of the critical infrastructure protection in which the instigators of the activity will have a primary role. It means an existence of a better functional activity and existence of a better structural position in the state- social relations. 


\section{Secururity}

$\sqrt{ }$ The subjects which will be involved in the process should urge for solutions which are in the context in the completion of the necessary framework for adequate protection; a better cooperation and coordination, efficient prevention and protection of the critical infrastructure from different shapes of imperilment.

The specialized training for the critical infrastructure protection has to be a top priority for the instigators of the private security activity in order to create the fundamental assumptions for an adequate approach in the work and providing adequate protection for these objects.

\subsection{Building community trust}

Nowadays it is considered that a certain society is democratic if it has a space for a broader debate around the issues which have great social significance, and transparency can only be achieved through active participation of the citizens in all the spheres of interest which would mean shared responsibility, but also the ability for creating the policy and its implementation.

The discussion around transparency is a relatively new appearance. It points out the need for an analytical approach which will take into consideration the especially complex relationship between the citizens as the uttermost recipients and users of the services and providers of the services which are directly focused on the provision and the quality of the service.

Regarding the private sector the transparency is a complex concept and it is the only way to initiate a public debate for the issues form the private security. It means that transparency is not a purpose for itself, but it is the only way which enables the existence of a public debate for all the essential issues related with the activities of the Security agencies and how are their designated goals achieved. It is more than necessary in order for the citizens to create the fundamental perception for the work of this sector.

Transparency is tightly connected with accountability. All the matters which are a public interest, including the activities performed by the private security sector have to be displayed for the citizens in the best possible way. It means that this sector has to work in accordance with the legal instructions and for their work they have to impart a complete revision, respectfully, account before the public for what has been 
made, how it was done and whether the expected outcomes are achieved. It is anticipated that what is presented before the citizens, if it is exposed completely, articulately etc., that it will contribute for the expectations to gain a broader support and to gain greater trust.

The central issue which is imposed here is the question "How to a greater transparency?" First, the openness of this sector toward the citizens would mean that its work is transparent, and its role demystified.

Basically, the openness of the security sector would mean a kind of a confirmation that what is done is in the interest of the citizens and it is in the interest of protecting the fundamental values.

It means that one of the democratic acquisitions in a certain society is for the citizens to know, respectfully, to be informed for the conditions in the private security sector.

With that they will have the opportunity also to discuss for essentially significant issues which are related with the work of the Security agencies. Second, the social responsibility should mean that the employees in the Security agencies would be completely focused on the execution of the tasks in the objects and that they will enforce laws consistently on the demand on their agency and their profession. It would mean that they have a proactive attitude and high awareness in the performance of the tasks. This element is also connected with the high degree of security culture. Security culture is an important assumption in order to foresee what the general culture in the country is, and also what is the culture of the individuals (security workers) for matters which have a security character. The security culture is conditioned from numerous factors starting from the family, through science institutions, to security institutions etc., and it is not determined by some regulations, rather it has to be a result of the expression and the strive for a more proactive role of the individual - employed in the Security agencies in order to promptly identify the occurrences, the bearers, the causes and the consequences tied with the situation in a security context. It means that only a proactive attitude toward this concern will result with an accumulation of the security cultural capital which will enable to create positive prejudices for the security paradigm. 


\section{Literature:}

1. Ahić J., Sistemi privatne sigurnosti, Sarajevo, 2009.

2. Bruce George and Button Mark, Private Security, Palgrave Macmillan, New York, 2004.

3. Bruce, K., Ahmed, A., D. (2014): Conceptions of Professionalism: Meaningful Standards in Financial Planning. Gower Publishing Company, British Library.

4. Bakreski, 0., (2012): Kontrola na bezbednosniot sektor, Filzozofski fakultet, Skopje.

5. Military Professionalism in Asia: Conceptual and Empirical Perspectives. East West Center. 2001.

6. Weckert, J., Lucas, R. (2013): Professionalism in the Information and the Communication Technology Industry. Australian National University, E Press,

7. Wear, D, Bickel, J. (2000): Educating for Professionalism: Creating a Culture of Humanism in Medical Education.

8. Denhart, R., Denhart, J., New Public Service: Serving Rather Than Steering, Public Administration Review, 60.

9. Dempsey S.John, Introduction to Private Security, Wadsworth, Cengage Learning, 2011.

10. Kuperus, H., Rode, A., Top Public Managers in Europe: Management and Working Conditions of the Senior Civil Servants in the European Union Member States (Study Commissioned by the French EU-Presidency), European Institute of Public Administration, Maastricht, 2008.

11. Maccarthaigh, M, Boyle R., Civil Service Accountability: Challenge and Change, State of the Public Service Series, Research paper No. 12, 2014.

12. Military Professionalism in Asia: Conceptual and Empirical Perspectives. East West Center. 2001.

13. Maslesa R., Teorije i sistemi sigurnosti, Magistrat, Sarajevo, 2001.

14. Profesionalizacija rukovodnog kadra u Crnoj Gori: Između države i politike, Podgorica, 2014

15. Ravand, M. (2014): Human Resource Professionalism: A Panacea for Public Organizations. Author House, Bloomingdale.

16. Hilsman, Roger. The Politics of Policy Making in Defense and Foreign Affairs. Prentice Hall, 1993. 
17. Стратегија за развој на приватното обезбедување во Република Македонија, Комора на Република Македонија за приватно обезбедување, Скопје, 2016.

18. Johnson Brian, Principles of Security Management, Pearson Prentice Hall, New Jersey, 2005. 